Acta Hispanica (2018) Supplementum I: 31-50

\title{
EL VIAJE COMO RECUSA CULTURAL DEL FRANQUISMO: ESPAÑOLES EN PORTUGAL EN 1974-1975 ${ }^{1}$
}

\author{
RITA Luís \\ Instituto Ciências Sociais, Universidade de Lisboa
}

\begin{abstract}
Resumen: Este artículo pretende examinar la presencia de españoles en Portugal durante el proceso revolucionario. Se dará particular atención a la idea del viaje y sus motivaciones, procurando integrarlos en experiencias distintas que incorporan fenómenos como el exilio, la movilización política o el turismo, con el propósito de concebir el "viaje" como una experiencia aún más transversal, común a una cultura política cuyo punto de unión sería el rechazo cultural del franquismo.
\end{abstract}

Palabras clave: revolución portuguesa; tardofranquismo; viajes

Abstract: This article aims to examine the presence of Spaniards in Portugal throughout the revolutionary process. Attention will be paid to the idea of the trip and its motivations, while accounting for distinct types, including exile, political mobilization, or tourism, conceptualizing the trip as a transversal experience uniting a political culture whose connection is the cultural refusal of Francoism.

Keywords: Portuguese Revolution; Late-Francoism; Trips

\section{Introducción}

\begin{abstract}
"La revolución de los claveles cambió radicalmente nuestra forma de entender la lucha antifranquista, muchos jóvenes, entonces creíamos que la dictadura nunca caería de forma pacífica, defendíamos que habría que acabar con ella con la lucha armada. La revolución pacífica portuguesa nos demostró que el régimen podría caer y la ruptura era posible."2
\end{abstract}

Estas palabras me las escribió A., cuarenta y tantos años después del jueves que amaneció con la prensa dando la noticia de que un golpe militar había ocurrido en Portugal y que el régimen, al revés de lo ocurrido en el anterior mes de marzo, no se aguantaría.

${ }^{1}$ Una versión de este trabajo fue presentada en las II Jornadas de Estudios Culturales Ibéricos que tuvo lugar entre 16 y 18 de noviembre de 2017 en la Technische Universität Chemnitz en Alemania.

2 Entrevista con A. (Segorbe, Valencia, 1953), hija de un médico republicano represaliado y expulsada de la Facultad de Medicina de la Universidad de Valencia por su actividad política, por e-mail (26.01.2017). 
En lo que dice respecto a la prensa, la recepción en España de este golpe militar, que se transformó en un proceso revolucionario, fue tan intensa cuanto diversificada, ${ }^{3}$ dentro de las posibilidades que un régimen autoritario, intentando contener su propia desintegración, ofrecía. La erupción de la revolución portuguesa proveyó a los medios de comunicación no sólo con memorias de la Segunda República y la subsiguiente guerra civil, pero también con reminiscencias de la historia reciente de Chile o de la Revolución Rusa, siendo continuamente utilizados marcos de interpretación relacionados con estos eventos. En gran medida de estos marcos resuena la idea hobbesiana de la revolución en cuanto caos.

Así en el espacio mediático español, esencialmente dominado por una cultura de identificación con el franquismo ${ }^{4}$ aunque en proceso de mutación, dominó, sobre todo a partir de 1975, una narrativa de equivalencia del concepto de democracia a una democracia europea, representativa e integrada en la cultura occidental, que excluía la posibilidad de que la revolución en Portugal pudiera ser considerada como parte de ese modelo y fuera, por eso, la negación de la democracia. ${ }^{5}$ Por su parte, la cultura política de alineación del franquismo, con menos posibilidad de expresión en el espacio público, principalmente el mediático -sobre todo cuando desafía la narrativa establecida como dominanteencontrará formas distintas de relacionarse con este proceso, entre las cuales, lo que se podrá llamar "turismo político". ${ }^{6}$ Sin embargo, los medios de comunicación, coadyuvantes en la transferencia cultural incluso en países bajo dictadura y

3 Josep SÁNCHEZ, "A influência de Abril na mudança de regime em Espanha”, in: Revista Crítica de Ciências Sociais, Nos 15, 16, 17, 1985, 209-221; Inmaculada CORDERO, “《Lo que no debe sen». La revolución portuguesa en la prensa española”, in: Encarnación LEMUS, et al. (coord.), El Fin de las dictaduras ibéricas, 1974-1978, Sevilla/Lisboa, CEA/Edições Pluma, 2010, 63-86; Marie-Claude CHAPUT, "La presse espagnole et la révolution des OEillets”, in: A Matériaux pour l'Histoire de notre temps, N 80, octobredécembre, 2005, 39-47 ; Teresa PINHEIRO, "Die Rezeption der Nelkenrevolution in der spanischen Presse", in Lusophone Konfigurationen. Festschrift für Helmut Siepmann, editada por Christoph Müller u.a. (Hgg.), zum 75. Geburtstag. Frankfurt a.M.: TFM, 2012, 325-349.

${ }^{4}$ Josep REIG, Identificación y alienación. La cultura política y el tardofranquismo, Valencia, Publicacions de la Universitat de València, 2007.

5 Rita LUÍS, Spain and the Portuguese Revolution of 1974-1975: the limits of a surveilled press, tesis doctoral, Universitat Pompeu Fabra, 2015.

6 Maria Alexandra LOUSADA, "Turismo político: consciência cívica e lazer (breves notas)", in: J. M. SIMÕES y C. CARDOSO FERREIRA (eds.), Turismo de Nicho. Motivações, produtos, territórios, Lisboa, CEG, 2009, 325-338. 
donde existe censura, como lo señala Kornetis ${ }^{7}$, ayudarán a conceptualizar el viaje como una forma de absorción de la revolución portuguesa, una idea plasmada en el título de una de las primeras crónicas que Manuel Vázquez Montalbán escribe después del golpe de estado del 25 de abril ${ }^{8}$ y que tendrá seguimiento en las narraciones de otros periodistas y/o columnistas a lo largo del bienio revolucionario así como en las noticias/reportajes sobre los estudiantes, entre otros, de viaje por Portugal.

La presencia de los periodistas españoles en Portugal será determinante en la conceptualización de la idea del viaje a Portugal, que concebirán alrededor de ideas como: 1) una ida masiva de españoles a Portugal, motivados por la novedad y la proximidad del evento y por una diferencia del cambio de divisas que hace el viaje económicamente atractivo;" 2) la sustitución del turismo "evasivo" o "escapista" por un turismo motivado políticamente; 3) la sustitución del turista en familia por el turista estudiante progresista ${ }^{10} \mathrm{y}$, finalmente, 4) la sustitución de Francia por Portugal como espacio donde consumir las posibilidades que la libertad ofrece. ${ }^{11}$

Este artículo pretende examinar, a partir de fuentes bibliográficas, hemerográficas, iconográficas y orales, formas alternativas al consumo mediático de relación con el proceso revolucionario portugués en España. Se dará particular atención al viaje y sus motivaciones, procurando integrar la experiencia española en Portugal en la historia de un "turismo político" de cariz revolucionario, ${ }^{12}$ pero problematizando la utilización de un concepto como el "turismo político" discutiendo, entre otras cosas, los puntos de relación entre este y el concepto de exilio. Por exilio se entiende la posibilidad de emancipación que confiere realizar fuera actividades prohibidas en España, una vez que, aunque parte de un movimiento transnacional, la experiencia de los viajantes españoles será conceptualmente distinta de la de los viajantes franceses, ingleses, alemanes, etc.

\footnotetext{
7 Kostis KORNETIS, "Everything links? Temporality, Territoriality and Cultural Transfer in the long 1960s", in: Historein 9, 2009, 34-45.

8 Manuel VÁZQUEZ, “A la revolución, en coche”, in: Tele-eXprés, 13.05.1974, 5.

9 Archivo General de la Administración (AGA), Ministerio de Información y Turismo (MIT), "Presidencia", caja: 51/9511.

${ }^{10}$ Idem.

${ }^{11}$ Manuel VÁZQUEZ, “El precio de la Libertad”, in: Tele-eXprés, 2.05.1974, 11.

12 Maureen MOYNAGH, Political tourism and its texts, Toronto, University of Toronto Press, 2008.
} 
En la esfera del político, el abordaje de Carrillo-Linares ${ }^{13}$ pone manifiesto contactos y recepciones clandestinas de la extrema-izquierda española, pero se podrá argumentar que el "viaje" será una experiencia aún más transversal, común a una cultura política cuyo punto de unión sería el rechazo cultural del franquismo. Así, además de las motivaciones estrictamente políticas, Portugal será procurado también con intuito de consumo cultural (excursiones cinematográficas, teatrales, compra de libros prohibidos, etc.). Una práctica, y también un gesto político, anteriormente ejercida de forma habitual en Francia, ${ }^{14}$ pero que se extenderá en esos momentos al otro país fronterizo.

\section{Portugal como territorio para la movilización política}

Más allá de las particularidades de la recepción de cada grupo político, la caída del Estado Novo en Portugal tuvo un profundo, y obvio, significado político en España, y para la lucha antifranquista en particular, inaugurando un nuevo territorio donde la movilización política era posible y que se traducirá de formas distintas.

Portugal pasará a configurar un territorio donde el exilio, en el sentido estricto de la palabra, es una posibilidad. En la madrugada del 16 de mayo el militante del FRAP, Eloy Moreno Rodriguez, ${ }^{15}$ cruza el río Guadiana para llegar a Portugal y pedir asilo político. Menos de un mes después llegará el vasco Manuel Inertillas García, ${ }^{16}$ por el norte, cruzando el río Minho. A los dos se les facilita documentación y la entrada, casi inmediata, del segundo está documentada. ${ }^{17}$ Pero Portugal pasará a configurar también un territorio donde es posible la organización de actividades políticas, antifranquistas, que incluyen movilizaciones como manifestaciones y/o protestas, pero también encuentros de organizaciones clandestinas, como será el caso de un encuentro de anarquistas españoles en la Voz do Operário en julio de $1974^{18}$ o el congreso de las

13 Alberto CARRILLO-LINARES, "Entre el universo simbólico y el mundo real: contactos y recepciones clandestinas de la extrema izquierda hispano-lusa en torno al 25 de abril", in: Encarnación LEMUS et al. (coord.). El fin de las dictaduras ibéricas (19741978), Sevilla/Lisboa, CEA/Edições Pluma, 2010,161-183.

${ }^{14}$ Cf. Lo Verde empieza en los Pirineos (1973) de Vicente Escrivá.

15 “Jovem militante espanhol refugia-se em Portugal”, in: A capital, 25.05.1974, 25.

16 "Separatista basco refugia-se em Portugal", in: A capital, 4.06.1974, 8.

17 "Refugiado basco já tem emprego", in: A capital, 5.06.1974.

18 “Anarquistas espanhóis em comício na Voz do Operário", in: A Capital, 20.07.1974, 6. 
juventudes socialistas del PSOE en el verano de 1975, que será realizado cerca de Sintra. ${ }^{19}$

El inicio de 1975 estuvo, además, marcado por protestas y demostraciones de solidaridad hacia los prisioneros políticos del régimen español. Alfonso Sastre y Genoveva Forrest, entre otros, estaban en la cárcel desde el 16 de septiembre y Sebastián Reyna se jugaba tres años de cárcel al estar acusado de ser el líder de las Juventudes Socialistas. A finales de 1974 la Sociedad Portuguesa de Autores había organizado un día de solidaridad con los presos políticos del régimen franquista que acabó por ser cancelado, pero finalmente, en enero de 1975, peticiones para su liberación fueron oficialmente presentadas en la Embajada de España. ${ }^{20}$

El 3 de marzo tuvo lugar una manifestación anarquista en Lisboa, que habrá reunido entre 500 y 1000 personas, cuyo trayecto empezaba en el Rossio, subiendo por Avenida da Liberdade hasta el Consulado de España, en la esquina con la Rua do Salitre, donde le esperaba un dispositivo policial considerable, prosiguiendo la manifestación hacía la Embajada en Praça de Espanha. En la protesta se podían identificar banderas negras y slogans como "Apoyo a los trabajadores españoles", "revolución social española y portuguesa" u otros más humorísticos como "Franco assado" y "Franco no espeto" que jugaban con la proximidad entre la palabra pollo en portugués y Franco. ${ }^{21}$ No hubo noticias de violencia, aunque las ventanas del Banco Fonsecas \& Burnay y las instalaciones de Alitalia en Marquês de Pombal hayan sido apedreadas por equivocación, ya que el objetivo eran las instalaciones de Iberia, situadas en la misma plaza, identificando, de esta forma, las motivaciones anticapitalistas y antifranquistas de la protesta.

En la última semana de marzo, ya después del intento de golpe del 11 de marzo y de la entrada en escena del Consejo de la Revolución, los españoles vuelven a manifestarse en Lisboa. La protesta tiene lugar en la Plaza de Rossio, una ubicación frecuente para la organización de protestas, y consistirá en personas de cara tapada dando vueltas a la plaza al ritmo de slogans como "frente popular", "democracia popular" y "solidaridad con el régimen portugués". ${ }^{22} \mathrm{El}$ apoyo a la nueva situación portuguesa, surgida después de la huida del General Spínola a

\footnotetext{
19 Al cual J.P. (Valencia, 1946) acude como invitado en la condición de militante de LCR (entrevista realizada por email (diciembre 2017).

20 AGA, MIT, “Cultura”, cajas: 42/9049 y 42/8952, "Presidencia”, caja: 51/9511.

21 AGA, MIT, "Presidencia”, caja: 51/9511.

22 AGA, MIT, “Cultura”, caja: 42/9117.
} 
España, fue demostrado igualmente en ciudades españolas como Barcelona, donde se realizó una muy corta manifestación delante del Consulado portugués, ${ }^{23}$ o Madrid, donde fueron colgadas banderas portuguesas en la Universidad Complutense. ${ }^{24}$ Sin embargo, incluso cuando realizadas en Portugal, la presencia de españoles en las manifestaciones, protestas o mitínes se caracterizó por la precaución, se visualizaban muchas caras tapadas y se percibía la sensación de riesgo, ya que muchas veces los participantes no tenían documentación legal. ${ }^{25}$ En determinados momentos será igualmente perceptible la relación de complicidad que se establecía entre los españoles y militares portugueses.

Otro nivel de la presencia militante española en Portugal será la participación en las protestas portuguesas y ya no específicamente antifranquistas. La manifestación del 1 de mayo convocará la presencia de mucha gente: vendrán delegaciones del PSOE, de CCOO (cf. imagen abajo) ${ }^{26}$ o un grupo de libertarios madrileños, vinculado con los Grupos de Presencia Confederal y Libertaria, que posteriormente organizará un Comité de Auxilio a los Anarcosindicalistas portugueses. ${ }^{27}$

La participación de españoles en estas movilizaciones será notada por los organizadores, que aprovechan para demostrar su solidaridad, ${ }^{28}$ como por los observadores, como sea la

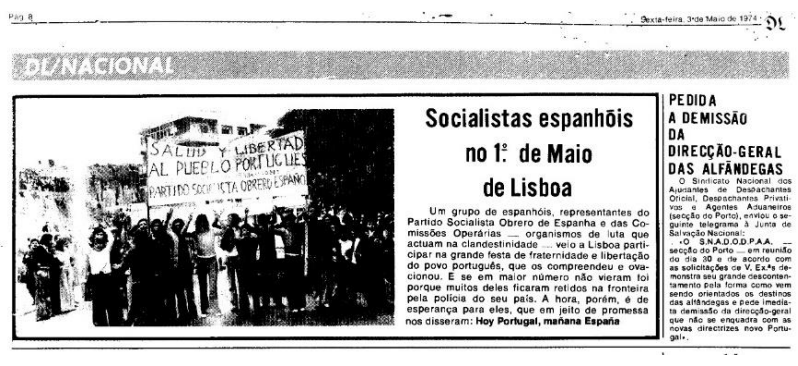
prensa, tanto la portuguesa como la española. Contrariamente a lo que pasaba durante el Estado Novo, cuando la presencia de extranjeros en Portugal era monitorizada por la policía política, ${ }^{29}$ durante el bienio revolucionario será posible la permanencia de extranjeros en situación irregular. Pero si el Estado portugués, con la disolución de la policía política (DGS) y el pasaje de competencias a la Policía de Seguridad Pública y, posteriormente, al Servicio de

\footnotetext{
23 Idem.

24 Idem.

25 "porque yo estuve allí con documentación ilegal y no me podía mover mucho." J.P., op. cit.

26 "Socialistas espanhóis no $1^{\circ}$ de maio em Lisboa", in: Diário de Lisboa, 3.05.1974, 8.

${ }^{27}$ CARRILLO-LINARES, op. cit.

28 AGA, MIT, “Cultura”, caja: 42/9117.

${ }^{29}$ Irene PIMENTEL, A História da PIDE, Mem Martins, Temas e Debates/Círculo de Leitores, 2007.
} 
Extranjeros, creado en noviembre de 1974, deja, momentáneamente, de poder controlar la presencia irregular de extranjeros hasta finales de $1975,{ }^{30}$ lo hará el régimen franquista a través de la monitorización de los medios de comunicación. Una consecuencia de la presencia de periodistas españoles en Portugal será que su trabajo será utilizado por el régimen, mediante la acción de la Dirección General de Seguridad, para ejercer la represión utilizando fotografías o reportajes audiovisuales en la identificación de la disensión. ${ }^{31}$ Según el testimonio de que Virgine Philippe recogió de Diego Carcedo, el periodista de TVE que fue retirado de Portugal en septiembre de 1975 en la secuencia de una entrevista que hizo la RTP a un miembro del FRAP en la semana anterior a las ejecuciones de cinco militantes antifranquistas, la represión afectó también a los periodistas de medios de comunicación del Estado, como es el caso de TVE. En la primavera de 1974, Carcedo había sido enviado a cubrir la toma de posesión del nuevo gobierno y del General António Spínola como presidente de la Republica, pero su programa ("Portugal, un mes después", Los reporteros $\mathrm{N}^{\circ} 21$ ) no llegó ser ni finalizado, ni, mucho menos, emitido. El motivo parece ser una fotografía que documentaba la presencia de su equipo en un mitin del MRPP donde Ernest Mandel pronunciaba un discurso en castellano. El retraso de la entrada de este reportaje, y otro de Manolo Alcalà, en el archivo autoriza a la autora de este trabajo a suponer que hubieron estado retenidas por alguna autoridad, corroborando el testimonio de Carcedo.

El verano de 1975 constituyó un momento de particular intensidad con una gran movilización internacional: de Italia vinieron varias centenas de militantes y simpatizantes de Lotta Continua, ${ }^{32}$ de Avanguardia Operaria y Pdup-Manifesto; ${ }^{33}$ y también de Francia, Alemania e Inglaterra. ${ }^{34}$ El contingente del País Vasco, en

30 Victor PEREIRA, “«Será que verei Lisboa?» Peregrinações de franceses no Processo Revolucionário em Curso”, in: Relações Internacionais, 25, 2010, 91-105.

31 Virgine, PHILIPPE, "La revolución de los claveles vista a través de televisión española (abril de 1974-abril de 1976)", in: C. RINA SIMÓN (ed.), Procesos de nacionalización e identidades en la península ibérica, Cáceres, Universidad de Extremadura, 2017, 403-425.

32 Giulia STRIPPOLI, “A Revolução na imprensa e na vida dos militantes de Lotta Continua”, in: Rita LUÍS, Luciana SOUTELO, Carla Luciana SILVA, A revolução de 1974-75: repercussão na imprensa internacional e memória(s), publicação electrónica, Lisboa, IHC, 2014, 83-97.

33 César OLIVEIRA, Os Anos decisivos. Portugal 1962-1985, Lisboa, Presença, 1993, 169.

34 AGA, MIT, "Cultura", caja: 42/9049; "É hora de descer às ruas em toda a europa", in: Diário de Lisboa, 6.08.1975, 5. 
particular, fue muy significativo, en el sentido que su presencia es muy señalada en los relatos. De Inglaterra vino A.D., militante de International Socialists, integrado en una comitiva de 30-40 personas en coordinación con el PRP-BR. El viaje tuvo lugar en agosto y con una duración de dos semanas, una de las cuales había sido elegida como semana de movilización internacional y, por lo tanto, "había gente de toda Europa", en concreto gente conectada con "siete organizaciones de la izquierda europea: Lotta Continua, Coordinamento Nazionale Comitati Operari e di Quartieri (Italia), Der Sozialismus Inderbro Wird Siegen (Alemania), International Socialists (Inglaterra), Kommunistik Forbun (Dinamarca), Pour le Comunisme (Francia) y Parole au Peuple (Belgica)". ${ }^{35}$ Esta semana de movilización internacionalista de solidaridad con los trabajadores portugueses, apoyada por el PRP-BR, incluyó visitas a una unidad militar, el Regimento de Artilharia de Lisboa (RALIS), a los astilleros navales de Setúbal (SETNAVE), a la radio Renascença y al diario República. ${ }^{36}$ Para el día 13 de agosto estaba marcada una confraternización internacionalista proletaria en el Pavilhão dos Desportos, en Lisboa, ${ }^{37}$ y la semana terminaría con una "manifestación antimperialista" el sábado 16. En esta manifestación, que tuvo el apoyo de LCI, PRP-BR y UDP, la presencia de españoles, franceses e italianos era muy evidente y los carteles exigían la liberación de los presos vascos José Antonio Garmendia y Ángel Otaegi Etxeberria, cuyo consejo de guerra tendría lugar el siguiente día 28. La manifestación "tenía delante los españoles, (que habían venido a propósito) y todos llevaban la cara tapada" y A. recuerda varios detalles que indician la complicidad establecida entre los militantes antifranquistas y el poder militar portugués. ${ }^{38}$ Durante esta semana se decidió que otra semana de movilización internacional de solidaridad hacía el "Portugal Rojo" tendría lugar en varias ciudades europeas en septiembre, del 22 al 29, y que culminaría en manifestaciones masivas el sábado día 27 de setiembre, ${ }^{39}$ que vino a coincidir con el día de

\footnotetext{
35 “Ser ou não ser pela revolução portuguesa", in: Diário de Lisboa, 9.08.1975, 20.

36 Idem.

37 “Lotta Continua no Pavillhão: Poder a quem trabalha, já!", in: Diario de Lisboa, 14.08.1975, 10-11.

38 "Cuando llegamos a la embajada norteamericana hay una línea del COPCON armados, obstaculizándonos la vía, yo estuve bastante delante y oí la conversación, hablaron en español con los españoles[...]: "Vosotros son españoles, tomad esto y tal"[...] una granada, le pasó una granada a un español, "Dale esto a Franco", Entrevista con A. D. (1952), que vivió en Madrid entre 1977 y 1979 y en Barcelona desde 1982, realizada en Barcelona (31/01/2017).

39 "Lotta continua no pavilhão...", op. cit.
} 
la ejecución de los cinco militantes antifranquistas, en España, y la gran protesta en Lisboa, que culminó con el asalto e incendio de las instalaciones diplomáticas españolas.

A. D., que pocos años después será militante de varias organizaciones de la extrema izquierda española como Acción Comunista, Organización Izquierda Comunista o Movimiento Comunista, hace una clara distinción entre los compañeros españoles con quien estuvo en Portugal y los demás: "Esta gente, no eran realmente turistas revolucionarios, est[ab]an ahí para escapar de la represión", aunque reconozca la existencia de un grado intermedio entre el turista y el militante que, en gran medida, corresponde al tópico de los estudiantes progresistas retratados en la prensa: "Me acuerdo de leer alguna cosa que la industria de turismo más clásico se quejaba porque solamente venían izquierdistas". De hecho, esta crítica se mantendrá, sobre todo a la derecha, ${ }^{40}$ cuando posteriormente se presentan los números del turismo relativos a 1975 y estos revelan un sector en baja.

En abril de 1976, la muerte del General Franco dejaba paso a que las elecciones realizadas en Portugal fuesen percibidas por los periodistas españoles como una extensión de la experiencia política española y, sobre todo, que fuesen percibidas como una oportunidad para aprender todo lo necesario para cuando llegara el momento de hacerlo en España: "La ilusión con que íbamos[...] eran nuestras elecciones[...] Eran la prueba más contundente de que lo que se estaba haciendo en Portugal se tenía que hacer en España, se podía hacer en España". La campaña electoral, en particular, proporcionaba momentos inéditos para muchos de los periodistas españoles: comparecer en ruedas de prensa en las cuales se suponía que los periodistas hicieran preguntas y no una transcripción de un dictado, poder entrevistar a políticos, cubrir los mítines de los partidos, cubrir el recuento de los votos, etc., o sea ejercer periodismo de forma activa en la búsqueda de información. Estas elecciones fueron, además, aprovechadas por Felipe González, que también se encontraba en Lisboa, para la realización de una rueda de prensa extraoficial con los periodistas españoles, que será divulgada por diarios como Informaciones ${ }^{42}$ o La Vanguardia española, ${ }^{43}$ anticipando una

\footnotetext{
${ }^{40}$ H., J., “Abril em Portugal, meditação político-turística”, in: A Rua, 22.04.1976, 18.

${ }^{41}$ Entrevista con Josep Ma SANMARTÍ (Barcelona, 1945-2017) realizada en Barcelona (26.01.2017).

42 Fernando JÁUREGUI, "Don Felipe González revela en Lisboa”, in: Informaciones, 26.04.1976, 3 .
} 
práctica de relaciones muy estrechas y pautadas por un nivel alto de informalidad que serán muy relevantes en los años venideros. ${ }^{44}$

Si la movilización política como motivación del viaje es particularmente identificable en la participación en asambleas y protestas, que los momentos de mayor intensidad de esta presencia coincidan con periodos de vacaciones escolares (semana santa y verano de 1975) introduce la cuestión del turismo. Dentro del ámbito del turismo con motivaciones políticas, Clausen y Velázquez ${ }^{45}$ hablan, a propósito de las "Zapatours", en Chiapas, y Christiana, en Dinamarca, de un "turismo de experiencias revolucionarias" que abarcaría la voluntad de quien, no deseando necesariamente ser parte integrante de procesos de cambio social, integrarse o poner riesgo su vida, desea sin embargo experimentar momentáneamente una forma de utopía. Esta categoría no recoge claramente todo el espectro del viaje español, una vez que el factor riesgo, como será salir en las fotos publicadas por la prensa, por ejemplo, estará siempre presente. Sin embargo, el contacto simbólico con momentos políticamente decisivos y la experiencia de transcendencia que le está asociada, contenidos en este concepto, aproximan, por el carácter de transcendencia, los viajes turísticos motivados políticamente de las peregrinaciones, que Dean MacCannell relaciona con la experiencia turística ${ }^{46}$ y que de alguna forma estará presente en el circuito de luchas parte de la semana de movilización internacional de agosto de 1975. Peregrinaciones, además, será precisamente el concepto que Montalbán utiliza para describir el significado del viaje a Portugal: "Va a haber mucho turismo español a Lisboa. Probablemente incluso Lisboa sustituya Perpiñán en nuestras peregrinaciones y no precisamente para ver el espléndido "streaking" de Laura Antonelli o Burt Reynolds, sino para comprar, al precio que sea, un pequeño souvenir de Libertad". ${ }^{47}$ El "souvenir de libertad" tendrá formas distintas que

43 Margarita SÁENZ-DIEZ, "Portugal: con sus 106 escaños de una asamblea de 263, el PS insiste en que va a gobernar solo”, in: La Vanguardia española, 27.04.1976, 23.

${ }_{44}$ Carles PONT, Josep M ${ }^{a}$ SANMARTÍ, Rita LUÍS, "Aproximación etnográfica del periodista de la Transición como fuente histórica: Estudio de la relación con los actores políticos y de los cambios en la producción de los medios escritos, in: Historia y Comunicación Social, 22 (1), 2017, 141-156.

${ }^{45} \mathrm{H}$. BALSLEV CLAUSEN y M. VELÁZQUEZ, "Turismo de experiencias revolucionarias, Christiania, Dinamarca y San Cristóbal de las Casas, México", in: Topofilia Revista de Arquitectura, Urbanismo y Ciencias Sociales, IV (1), 2013, 623-638.

46 Dean MACCANNELL, The Tourist: the New Theory of the Leisure Class, Berkeley, University of California Press, 1999.

${ }^{47}$ VÁZQUEZ, El precio, op. cit. 
aproximarán en distintos grados la experiencia del viaje al concepto de Clausen y Velázquez, pero que conferirá un contenido político a la experiencia del viaje. Lousada, por su parte, añade a la militancia, más fácil de identificar, prácticas de la peregrinación laica y la curiosidad informada, que en el caso español tendrán siempre que ser contrastadas con el fenómeno de exilio, aunque declinado en la posibilidad de emancipación que confiere realizar fuera actividades prohibidas en España. En el caso presente, acceder a un consumo cultural prohibido por el régimen franquista.

\section{El viaje como recusa cultural del franquismo}

La presencia española en Portugal será señalada como evento también por la prensa portuguesa. En Diario Popular, por ejemplo, son publicados cartoons que relacionan esta presencia con una motivación cinéfila: la posibilidad de asistir a una sesión de El último tango en París (cf. imagen a la izquierda). ${ }^{48} \mathrm{El}$ mismo diario

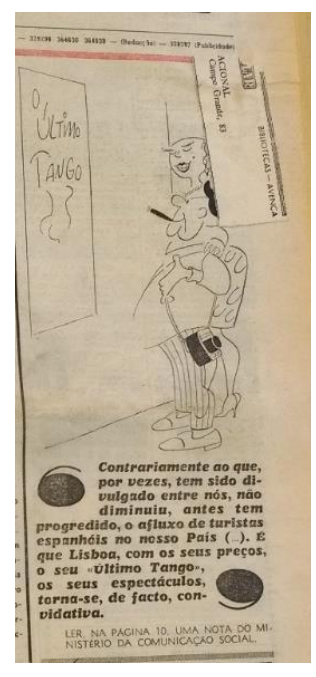
describe los turistas españoles como provenientes "sobre todo del medio estudiantil e intelectual, pero también del turista 'neutro". ${ }^{49} \mathrm{El}$ corresponsal de La V anguardia espanôla y de $Y a$, Alberto Miguez, resume la atracción por Portugal de sus paisanos en tres motivaciones, incluyendo en ellas la película de Bernardo Bertolucci: "Y es que Lisboa, con sus precios, su "último tango" en las carteleras y su sol de invierno, tímidamente sugerido, es todo un espectáculo..." ${ }^{50}$ De la libertad que la caída del régimen inauguró, del clima apacible y de la diferencia de cambio de moneda resulta un Portugal muy apetecible al consumidor español, ${ }^{51}$ ya que el valor de la peseta con relación al escudo ${ }^{52}$ será durante todo este periodo francamente favorable al bolsillo español. Así, además de motivaciones relacionadas con la movilización política estricta, Portugal será buscado con

48 “O último tango", in: Diário popular, 12.11.1974, 1.

49 "Turistas (de várias latitudes) interessam-se por Portugal", in: Diário porpular, 27.11.1974, 16.

50 AGA, MIT, "Presidencia”, caja: 51/9511.

51 "Alfama, allá podías comer donde quisieras, todo era muy barato, baratísimo para nosotros[...] el precio de la pensión era baratísimo, viniendo de Barcelona había una cierta diferencia.” Entrevista con J. G. (Figueres, 1950) realizada en Barcelona (26.01.2017). 52100 pesetas valían cerca de 237 escudos en 1974, 229 en 1975 y 227 en 1976. 
El viaje como recusa cultural del franquismo: españoles en Portugal en 1974-1975

fines de consumo político-cultural, lo que permite argumentar que el viaje a Portugal será una experiencia transversal, común a una cultura política cuyo punto de unión seria la recusa cultural del franquismo.

La idea del viaje como recusa cultural del franquismo tiene una historia que es anterior al proceso revolucionario en Portugal. Por un lado, se pueden identificar sectores de la población española, con recursos para ello, ${ }^{53}$ que viajaban en avión, o en coche, a ciudades como Londres o París buscando lo que no encontraban disponible en Madrid o Barcelona: un consumo cultural que incluía la compra de libros prohibidos en España, la visita de librerías como la Masperot - “que al final de todo tenía la sección de cómics y en esa sección de cómics encontrabas a todos los intelectuales de Barcelona" ${ }^{4}-$ o la Espagnol, en París, y el visionado de películas, también prohibidas, en particular las eróticas o pornográficas. Por otro, en las zonas más cercanas a la frontera con Francia estos viajes se hacían en coche y tenían como destino ciudades como Biarritz, donde transcurre la acción de la película de Vicent Escrivá, ${ }^{55}$ Ceret, donde Fernando Arrabal $^{56}$ presentó películas después de haber sido prohibidas en España, ${ }^{57}$ o Perpiñán, donde existía un circuito dedicado al turismo español, pero también el Principado de Andorra, donde el crítico de cine del diario barcelonés Tele/eXprés, Juan Francisco Torres, llegó a tener un negocio dedicado al cine. ${ }^{58} \mathrm{La}$ caída de la dictadura proporcionará que estos viajes pasen a tener como destino también a Portugal, sobre todo para quienes habitaban las regiones españolas más cercanas a Portugal.

\footnotetext{
53 “todos los hijos, bien de burgueses, bien que teníamos dinero por vía trabajo personal -mi caso es ese, no soy hijo de burgueses, sino de arruinados-, salíamos de aquí continuamente. Traíamos revistas, yo traía revistas de cine francés, que ahora las quería donar[...] con mi padre iba a ver cine más o menos erótico al sur de Francia, pero iba mucho a París o a Londres y me lo traía todo lo que podía." Entrevista con S. (Buenos Aires, 1951) realizada en Barcelona (30.01.2017).

${ }^{54}$ SANMARTÍ, op. cit.

55 ESCRIVÁ, op. cit.

56 "Y cuenta que vio la última de sus películas en Ceret, un pueblecito francés (2000 habitantes) justo en la frontera con Cataluña, entre 1500 españoles, que se habían desplazado para asistir a la proyección" Moisés PÉREZ, “Arrabal, a la puerta", in: Blanco y Negro, 25.12.1976, 51.

57 Berta MUÑOZ, El teatro crítico español durante el franquismo, visto por sus censores, Madrid, Fundación Universitaria Española, 2005.

58 J.G., op. cit.
} 
La película de Vicente Escrivá, Lo verde empieza en los Pirineos, estrenada el 14 de setiembre de 1973, retrata el viaje de tres amigos a Biarritz en busca, entre otras cosas, de las películas prohibidas en España, la película de Bernardo Bertolucci, en concreto, ya que será ésta, además, la utilizada en el cartel promocional. Llegados a "las puertas de Europa", como le llaman los protagonistas, encuentran españoles por todas partes, en el cine encuentran al español "progré" haciendo cola para La grande bouffe (1973), pero los tres amigos eligen películas como La maseusse perverse (Clinic Xclusive, 1971), Inga (Jag-en oskuld, 1968), La naranja mecánica, (Clockwork Orange, 1971) y, claro, El último tango en París (1972), que ven repetidamente.

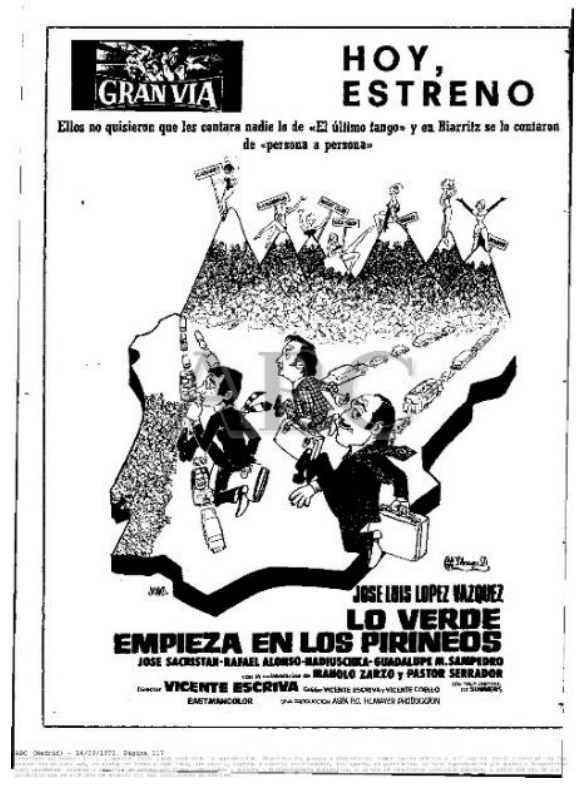

Tanto la frase promocional de la película: "ellos no quisieron que les contara nadie lo de «el último tango» y en Biarritz se lo contaron de "persona a persona»" (cf. imagen a la izquierda $)^{59}$ como la presencia mediática de la actriz Maria Schneider en la prensa son reveladores del papel de transferencia cultural de los medios de comunicación. En España se acompaña por la prensa la producción cinematográfica mundial y, durante todo el año de 1975, Maria Schneider es considerada newsworthy ${ }^{60}$ por acontecimientos relacionados con su carrera profesional, "la conocida protagonista del último tango" la apodan, pero sobre todo por su vida íntima. Schneider es conocida por el público español y la costumbre de mirar películas prohibidas en las zonas fronterizas es consentida por el régimen al punto de ser una presencia tanto en los cartoons publicados en la prensa (cf. imagen en la página siguiente) ${ }^{61}$ como ser parte de la trama y publicidad de una película como la de Escrivá. O sea, la idea del viaje para ir a ver El último tango en París estaba, de hecho, ya creada antes de que la revolución sucediera en Portugal.

59 ABC, 14.09.1973, 117.

60 Gaye TUCHMAN, Making News: A Study in the Construction of Reality, New York, The Free Press, 1978.

${ }^{61}$ Arriba 25.07.1975. 

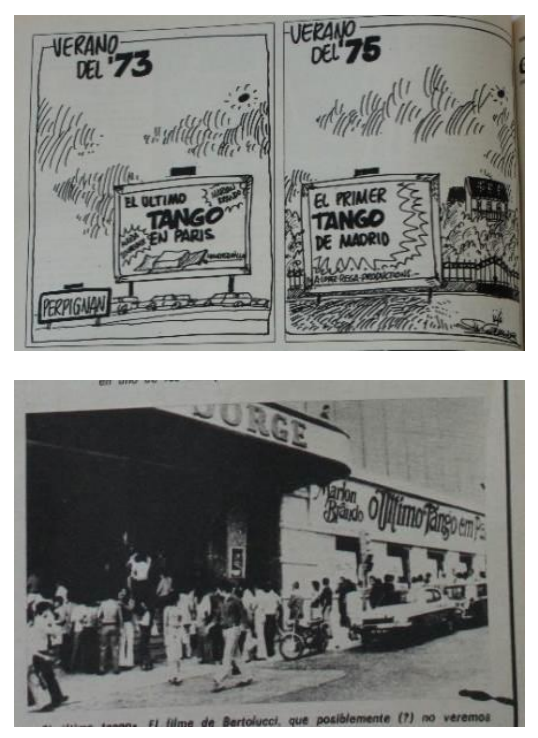

En Portugal la película se estrenó el día 8 de agosto de 1974 y estuvo en cartelera 14 semanas, hasta mediados de noviembre, un momento que coincide con la señalización de la presencia de españoles en Lisboa por la prensa portuguesa. Las colas para ver la película serán noticia en la prensa española (cf imagen a la izquierda), ${ }^{62}$ señalando como Maria Schneider y la película de Bertolucci eran parte de la rutina informativa de la prensa en España, que vehiculaba igualmente la idea que para participar más activamente de lo que ya se participaba leyendo la prensa, sólo hacía falta viajar hasta Francia, y con la revolución, hasta Portugal. Otra película con el mismo tipo de significado simbólico ${ }^{63}$ será Emmanuelle (1974), que se estrena el 17 de abril de 1975 en los cines Pathé y Roma en Lisboa, permaneciendo en cartelera hasta inicio de septiembre. Ambas películas serán acompañadas del aviso de que "contiene[n] escenas eventualmente chocantes" que vino a sustituir la censura. ${ }^{64}$ Cuando, en enero de 1978, la película de Bertolucci finalmente se estrena en España, ${ }^{65}$ se ironiza en Diario 16 (cf. imagen abajo) ${ }^{66}$ sobre la necesidad de seguir

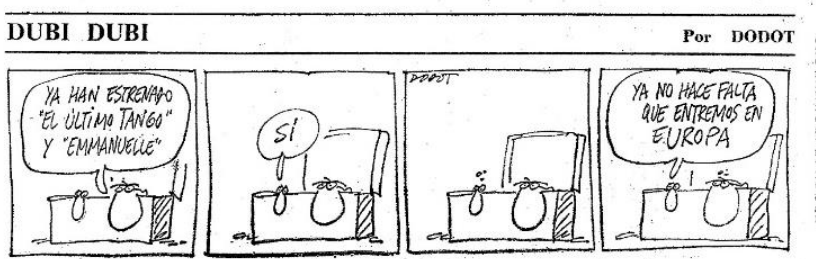
negociando la entrada en CEE, lo que ilumina tanto el significado de Europa como del acto de mirar películas en el imaginario colectivo español de esos años.

62 Arriba, 24.04.1975.

${ }^{63} \mathrm{~J}$. G., op. cit.

${ }^{64}$ Paulo CUNHA, "Uma Censura depois da extinção da Censura: o caso dos filmes eróticos e pornográficos (1974-76)", in: Avanca Cinema 2011, asequible en:

https://www.academia.edu/5723807/Uma_Censura_depois_da_extinção_da_Censura_o_ caso_dos_filmes_eróticos_e_pornográficos_1974-76_2011_, fecha de consulta: 20 de octubre de 2018.

65 Se estrenará primero en Madrid, a finales de 1977, y Professione: reporter (Michelangelo Antonioni, 1975), se estrenará también ya después de la muerte de Franco, en mayo de 1976.

66 Diario 16, 7 de enero 1978, 4. 
Otro de los destinos de los españoles en Lisboa era el Cine Universal donde entre 1974 y 1977 fueron proyectadas las películas de Animatógrafo. Este es un proyecto de programación del realizador, productor y distribuidor Antonio Cunha Telles, que recuerda la presencia de españoles, ${ }^{67}$ en particular de madrileños en estas sesiones. ${ }^{68}$ Además de sesiones de homenaje a clásicos como Eisenstein o Jean Vigo, integran la programación de esos años películas de realizadores españoles como Fernando Arrabal. Viva la muerte (1970), que se estrenará en España el 2 de diciembre de $1980,{ }^{69}$ estará en cartelera varias semanas en el último trimestre de 1974 y J'irai comme un cheval fou (1972), estrenada en Madrid el 16 de marzo de $1978,{ }^{70}$ se podrá ver en el Universal entre abril y mayo de 1975, regresando después en julio, habiendo estado 11 semanas en el cine Satélite, otra sala en Lisboa que albergaba la programación de Animatógrafo. En este sentido, Portugal anticipará en algunos años los estrenos de películas en España.

Haber estado en Portugal ocasionaba, en el caso de los periodistas o de aquellos con acceso a medios de comunicación, ${ }^{71}$ que se escribiesen crónicas, libros $^{72}$ y que se organizaran charlas, más o menos informales, para hablar sobre la experiencia. ${ }^{73}$ Los periodistas en Portugal serán de diferentes tipos: estarán los

\footnotetext{
67 AAVV, António Cunha Telles continuar a viver. Lisboa, Cinemateca PortuguesaMuseu do Cinema, 2014, 52.

68 António CUNHA TELES, “Como era produzir em Portugal nas décadas de 1960 1980?”, in: I Encontro de História Oral do Cinema Português, 16.04.2018.

${ }^{69}$ El País, 7.12.1980.

70 ABC, 21.10.1978, 45.

${ }^{71}$ Jordi Borja, no siendo periodista, publicaba crónicas en Tele/eXprés, algunas de estas fueron resultados de su presencia en Portugal.

${ }^{72}$ Entre otros, libros como: Eliseo BAYO, Portugal: en libertad condicional. Barcelona, Dirosa, 1974; Andreu CLARET, Hablan los capitanes - Portugal: Génesis, ideología y práctica política del Movimiento de las Fuerzas Armadas. Barcelona, Ariel, 1975. Luís CARANDELL y Eduardo BARRENECHEA, Portugal, sí. Madrid, Cuadernos para el Dialogo, 1974; César de la LAMAS, La Revolución de la flor, Golpe de Estado en Portugal. Madrid, Ed. Sedmay, 1974; Manuel LEGUINECHE, Portugal: la revolución rota. Madrid, Felmar Ed., 1976; Xavier ROIG, Portugal: la muerte de un fascismo. Crónica de un golpe de estado, Barcelona, Laia, 1974.

73 "Nos llamaban los amigos: «A ver cuándo me cuentas.» (...) Los que planeaban viajes a Lisboa nos pedían que les diéramos direcciones de amigos portugueses con quienes poder hablar. "¿Sabes dónde se puede comprarse el libro de las tres Marías?»", CARANDELL y BARRENECHEA, op. cit., 149.
} 
veteranos, ${ }^{74}$ normalmente más próximos al régimen, pero también los politizados y antifranquistas; una parte importante de los periodistas que venían de Barcelona estaban conectados con el Grup Democrátic de Periodistes (19661976). ${ }^{75}$ Algunos eran además bastante jóvenes y la revolución en Portugal fue una de sus primeras, o incluso la primera, experiencia profesional como periodista en el extranjero. Este será el caso de Xavier Roig. Al regresar a Barcelona, escribe el libro Portugal: la muerte de un fascismo. Crónica de un golpe de estado, "en 18 días" con la idea de que "sea útil". A su vuelta, además de las solicitudes de charlas sobre la experiencia, Roig, que había sido confrontado en Portugal con culturas periodísticas distintas a la española, reflexiona ${ }^{76}$ sobre las condiciones de trabajo, identificando tres puntos importantes sobre la autopercepción de los periodistas españoles con respecto a las limitaciones sentidas a la hora de realizar su trabajo: la falta de medios, sobre todo en comparación con los enviados especiales de los grandes medios de comunicación extranjeros; la falta de contactos y el desconocimiento de las rutinas de trabajo y, por último, la percepción de la limitación que constituye el sistema de control vigente en España, sobre todo en la forma como el periodista se protege introduciendo la autocensura en su forma de trabajar. Las limitaciones profesionales que menciona Roig, la falta de contactos y el desconocimiento de las rutinas de trabajo, fueron señalados igualmente por Josep María Sanmartí que cubrió las primeras elecciones constitucionales en abril de 1976 para el recién creado diario catalán Avui. Contrariamente a los españoles que "iban a todas partes", los corresponsales extranjeros tenían mucha facilidad en ponerse en contacto con quien deseaban entrevistar: "tenían una agenda de teléfono que nosotros no teníamos [...] hacían unas llamadas y entonces se ponían Mário Soares[...], todos les cogían el teléfono y entonces hacían unas crónicas, bueno, bueno". ${ }^{77} \mathrm{El}$

74 Entre los veteranos encontramos a periodistas como José Salas, corresponsal de $A B C$, o Juan Ramón Pérez Clotas, enviado especial de Arriba/PYRESA, o Augusto Assia, enviado especial de La Vanguardia Española, o Felipe Fernández Armesto (19062002), cuyas trayectorias profesionales han empezado en la posguerra, o, en el caso de Assia, en la Alemania de los años 20/30.

75 Eliseo Bayo (Zaragoza, 1939) de Sábado Gráfico, Manuel Campo (Camporells, 1951) de Tele/eXprés, Andreu Claret (Francia, 1946) de Cambio 16; Xavier Roig (Barcelona 1946) de Tele/eXprés, Margarita Sáenz-Diez (Barcelona 1942) de La Vanguardia española, Manuel Vázquez Montalbán (Barcelona, 1939) de Tele/eXprés y Triunfo.

76 "En 18 días escribió una crónica de la revolución: «Portugal la muerte de un Fascismo»", in: Tele/eXprés, 7.08.1974, 6.

77 SANMARTÍ, op. cit. 
fenómeno de los "periodistas curiosos", además, hizo que redacciones casi enteras de algunos medios fuesen trasladadas a Portugal, aprovechando un vuelo charter organizado por TVE, para vivir de cerca el momento de las primeras elecciones en $1975,{ }^{78}$ o que periodistas que se fueron de vacaciones, escribiesen su crónica, ${ }^{79}$ un fenómeno tan extendido que llegó al punto de que ni todas tenían cabida en la prensa. ${ }^{80}$

Las memorias de estos viajes merecen que se recupere la crítica que Lousada hace del turismo político como concepto, tal como lo define Moyanagh, es decir, partiendo de las motivaciones de un sujeto, que desea participar o demostrar solidaridad hacia un proceso político en curso en cualquier parte del mundo. Lousada deja en evidencia que este sujeto será tendencialmente uno con medios económicos para viajar y con posibilidad de acceder a la producción de memoria. En el contexto de la presente investigación, por ejemplo, todos los entrevistados tenían, de hecho, tanto disponibilidad material como tiempo libre para el ocio, habían viajado al extranjero anteriormente, tenían acceso a coche ${ }^{81}$ y/o posibilidad de viajar en avión y formación media o superior. Otro punto señalado por Lousada que tiene cabida en esta reflexión será la relación de este tipo de turismo con el mercado turístico, una vez que independientemente de que sea una categoría operacional para describir los viajes de españoles, ya sean prácticas turísticas con motivaciones políticas subyacentes que no implican una defensa explicita y activa del proceso en causa, o no, estas terminan contribuyendo para la economía en Portugal, ayudando, indirectamente, a la revolución en curso.

\footnotetext{
78 Triunfo, Cambio-16, Contrastes, Posible, cf. Gabriel SÁNCHEZ, "Doscientos periodistas españoles, en Lisboa", in: Arriba, 25.04.1975.

${ }_{79}$ De viaje por Portugal en el verano de 1974 Maria Dolores Masana, de la sección internacional de La Vanguardia Española y mujer de Carlos Nadal, también miembro del GDP, publica un artículo en forma de carta que es anunciado como una serie, pero que no tiene continuación: $\mathrm{M}^{a}$ Dolores MASANA, "Impresiones de un viaje al "Nuevo" Portugal (1)”, in: La Vanguardia Española, 2 de julio 1974.

${ }^{80}$ J.G., op. cit.

${ }^{81}$ En 1974 el nivel de motorización en España era de ocho habitantes por coche (datos de la Dirección General de Tráfico; anuario general 1997).
} 
El viaje como recusa cultural del franquismo: españoles en Portugal en 1974-1975

\section{El turismo en disputa}

La dimensión política del viaje se insinúa además en el uso que se hace de ella en ambos países. Las estadísticas de la Dirección General de Turismo muestran, en el verano de 1975, que los números bajan, con relación al año anterior, en $30 \%$, habiendo bajado el turismo español en 34\%. Un nivel de baja sólo superado por el turismo norteamericano (51\%). Hubo, sin embargo, una inversión de la Agencia de Turismo portuguesa con la intención de captar el turismo español motivado por la nueva situación política, visible en las campañas de 1974, "Portugal, tan nuevo y tan diferente", y de 1975, "Portugal tan nuevo y tan

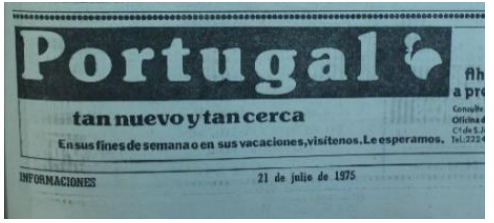
cerca" (cf. imagen a la izquierda), ${ }^{82}$ que serían glosadas por Sir Camara, "España, tan nueva y tan en su sitio" (cf. imagen a la derecha), ${ }^{83}$ dejando en evidencia tanto la diferencia de la situación política entre los dos países como el fallo de la política de apertura anunciada por el régimen.
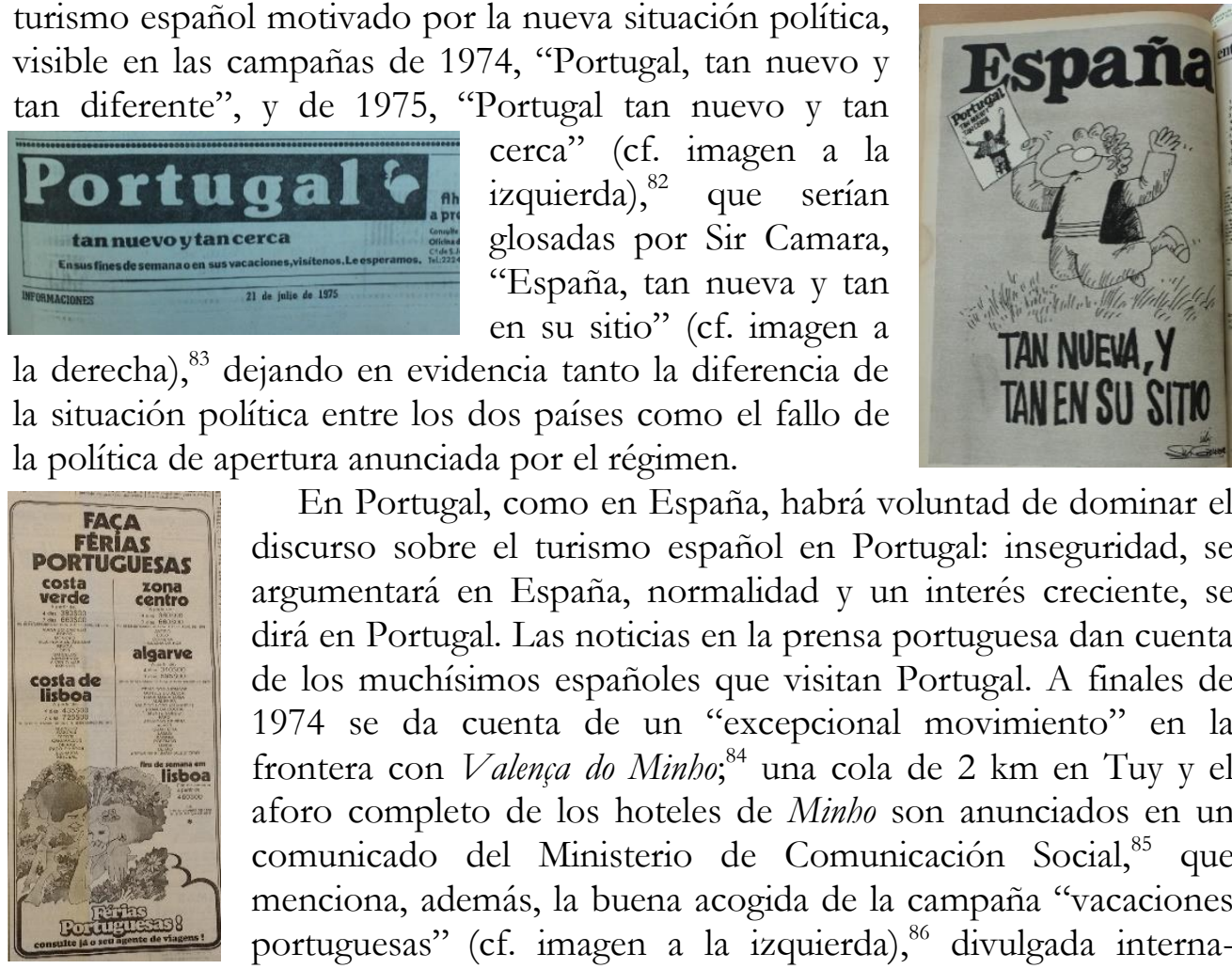

En Portugal, como en España, habrá voluntad de dominar el discurso sobre el turismo español en Portugal: inseguridad, se argumentará en España, normalidad y un interés creciente, se dirá en Portugal. Las noticias en la prensa portuguesa dan cuenta de los muchísimos españoles que visitan Portugal. A finales de 1974 se da cuenta de un "excepcional movimiento" en la frontera con Valença do Minho; ${ }^{84}$ una cola de $2 \mathrm{~km}$ en Tuy y el aforo completo de los hoteles de Minho son anunciados en un comunicado del Ministerio de Comunicación Social, ${ }^{85}$ que menciona, además, la buena acogida de la campaña "vacaciones portuguesas" (cf. imagen a la izquierda), ${ }^{86}$ divulgada interna-

\footnotetext{
82 Informaciones, 21.07.1975.

83 Arriba, 23.07.1975, 23.

84 “Uma invasão de espanhóis apesar dos boatos que circulam lá fora...", in: Diário popular, 4.11.1974, 14

85 “Os preços (baixos) e o «ultimo tango» atraem os espanhóis a Lisboa", in: Diário popular, 12.11.1974, 10.

86 Diário popular, 26.11.1974, 17.
} 
mente y en algunas ciudades españolas, que habría triplicado el trabajo de atención al público de la delegación de Turismo de Portugal en Madrid. Esta campaña de normalidad, responsabilidad del MCS, contrasta con, o responde a, una denuncia hecha por la federación francesa del Partido Socialista, publicitada en el verano de $1974,{ }^{87}$ de una supuesta campaña de disuasión de la realización de turismo en Portugal que será ayudada por noticias del brote de cólera y de agitación social que, de acuerdo con esta federación, estaban siendo difundidas por varios países europeos, en particular en los puestos fronterizos españoles. ${ }^{88}$ La alarma provocada por un brote de cólera, en el verano de 1974, ayudó a la partida de quienes se encontraban de viaje ${ }^{89}$ y la situación fue manejada, como mínimo en España, para generar alguna confusión semántica. ${ }^{90}$

En noviembre, Diário Popular mantiene las noticias sobre un aumento del flujo de turismo a pesar de los rumores de inseguridad. ${ }^{91}$ De hecho, estos parecen ser la razón del comunicado del MCS. El Consejo de Información de la Embajada de España en Lisboa ${ }^{92}$ cree que el comunicado pretende combatir una supuesta crisis en el sector turístico, motivo por el cual en el comunicado se utiliza una cita del corresponsal de La Vanguardia: "Nunca se había visto tantos compatriotas callejeando por la capital portuguesa. Me han contado que en la frontera de Caya-Badajoz las colas de automóviles españoles eran impresionantes, mucho más que en plena temporada turística". ${ }^{93}$ Unos meses más tarde, inmediatamente después del 11 de marzo y de la aceleración del proceso revolucionario, aunque haya varias noticias informando que la frontera con Portugal se encuentra normalizada y abierta al turismo familiar, algunos medios de comunicación españoles (Cifra, Pueblo, Europa press) difunden un grado de

\footnotetext{
87 “Socialistas denunciam campanha anti-portugal”, in: A capital, 29.06.1974, 11.

${ }^{88} \mathrm{El}$ vespertino $A$ Capital noticia las dificultades con las que ciudadanos portugueses enfrentan las autoridades españolas: "Polícia espanhola retarda partida de emigrantes para Portugal", in: A Capital, 7.05.1974, 8; "Português detido pela DGS espanhola", in: A Capital, 24.07.1974, 9.

89 “en aquel momento había una epidemia de cólera, creo recordar y ella va empezar a encontrarse mal y hemos ido a un dispensario que estaba allá por Terreiro do Paço y nos han dicho que no era cólera y que sería otra cosa -que era hepatitis sólo nos hemos enterado más tarde- y no era cólera pero no nos quedamos tranquilos y hemos decidido volver", J.G., op. cit.

${ }^{90}$ SANCHÉZ, op. cit., 361.

91 "Uma invasão...", op. cit.

92 AGA, MIT, "Cultura”, caja: 42/8952.

93 Alberto Miguez (AGA, MIT, "Presidencia”, caja: 51/9511).
} 
antagonismo con respecto al turismo español tradicional que toma la forma de relatos de inseguridad, como la llegada de trenes con pintadas a Galicia, ${ }^{94}$ la recusa de las agencias de alquiler de coches en Portugal ya que la policía transmitió informaciones de que estos no serían bien acogidos, ${ }^{95} \mathrm{o}$ la cancelación de paquetes de oferta turística en Portugal de agencias gallegas, ${ }^{96}$ después de un episodio de violencia ocurrido en Oporto. A nivel mediático se difunde la idea de que los españoles no son bienvenidos en Portugal $^{97}$ y que las agencias turísticas españolas no se encuentran dispuestas a asumir el riesgo. ${ }^{98} \mathrm{El}$ discurso de inseguridad se instala en España precisamente en un periodo de interés creciente por Portugal: la Semana Santa de 1975, coincidente con la campaña electoral para la Asamblea constituyente.

\section{Conclusión}

La experiencia revolucionaria portuguesa fue, posiblemente, demasiado corta para que ocurriera una verdadera sustitución, tanto material como en el imaginario colectivo, de Francia por Portugal como espacio de exilio y de movilización política, pero también de consumo. Sin embargo, Portugal fue durante un tiempo un territorio de exilio para militantes antifranquistas, un territorio de organización política y un territorio de consumo de lo que estaba prohibido en España, anticipando, por ejemplo, el estreno de películas símbolo de la represión política, pero sobre todo moral, como El último Tango en París o Emmanuelle. El hecho de que la forma de transformar estas prohibiciones forme parte de la cotidianeidad de la prensa y de la producción cultural misma introduce la cuestión de que culturalmente el rechazo al régimen franquista empezaba a ser visible, o sea, que hay un desencuentro de valores ya patente. El viaje, sobre todo el de consumo cultural, recoge este desencuentro de valores, configurando la banalización de una recusa del franquismo, la cultural. El cambio político que empezó en España, con la muerte de Franco, justo cuando el proceso revolucionario en Portugal empezaba a entrar en una fase de estabilización institucional, solapará quizás, en la memoria colectiva, algunas características de estos viajes.

\footnotetext{
${ }^{94}$ AGA, MIT, “Cultura”, caja: 42/9117.

95 Idem.

96 Idem.

97 Idem.

98 Idem.
} 